\title{
Kinetics and DFT studies of photoredox carbon-carbon bond cleavage reactions by molecular vanadium catalysts under ambient conditions
}

\author{
Sarifuddin Gazi, ${ }^{a}$ Miloš Đokić, ${ }^{a}$ Adhitya Mangala Putra Moeljadi, ${ }^{a}$ Rakesh Ganguly, ${ }^{a}$ Hajime \\ Hirao $^{\star a b}$ and Han Sen Soo ${ }^{\star a c d}$ \\ ${ }^{a}$ Division of Chemistry and Biological Chemistry, School of Physical and Mathematical Sciences, \\ Nanyang Technological University, Singapore 637371 \\ b Department of Biology and Chemistry, City University of Hong Kong, Tat Chee Avenue, \\ Kowloon, Hong Kong SAR, China \\ ' Solar Fuels Laboratory, Nanyang Technological University, 5o Nanyang Avenue, Singapore \\ 639798 \\ ${ }^{\mathrm{d}}$ Singapore-Berkeley Research Initiative for Sustainable Energy, 1 Create Way, Singapore 138602
}

\begin{abstract}
Visible light assisted photocatalytic organic reactions have recently received intense attention as a versatile approach to achieve selective chemical transformations, including C-C and several C-X (X = N, O, S) bond formations under mild reaction conditions. The light harvesters in previous reports predominantly comprise ruthenium or iridium photosensitizers. In contrast, selective, photocatalytic aliphatic $\mathrm{C}-\mathrm{C}$ bond cleavage reactions are scarce. The present study focuses on rationally designing $\mathrm{V}^{\mathrm{V}}$ oxo complexes as molecular, photoredox catalysts towards the selective activation and cleavage of a C-C bond adjacent to the alcohol group in aliphatic alcoholic substrates. We have employed kinetics measurements and DFT calculations to develop a candidate for the catalytic C-C bond activation reaction that is up to 7 times faster than our original vanadium complex. We have also identified a substrate where the C-C bond cleaves at rates $2.5-17$ times faster, depending on the catalyst used. In order to better understand the effects of ligand modification on the thermodynamics and catalysis, DFT calculations were employed to reveal the orbital energies, the electronic transitions during the $\mathrm{C}-\mathrm{C}$ bond cleavage, and the activation barriers. Our combined kinetics and computational studies indicate that the incorporation of electron withdrawing groups at select sites of the ligand are essential for the development of active and stable vanadium photocatalysts for our $\mathrm{C}-\mathrm{C}$ bond cleavage reactions.
\end{abstract}

KEYWORDS. Photoredox catalysis, selective C-C bond cleavage, reaction kinetics, vanadium(V) oxo complexes, DFT calculations, and visible light photocatalysis.

\section{Introduction}

Photoredox catalysis has emerged as a versatile and novel method to harvest light energy to mediate $\mathrm{C}-\mathrm{C}$ bond formation reactions with remarkable selectivity, in spite of the intermediacy of highly reactive radical species. ${ }^{1-10} \mathrm{~A}$ number of seminal studies have employed transition metal and organic photosensitizers to activate common substrates to generate putative radical species, which are sometimes coupled with another catalyst (frequently nickel-based) to create $\mathrm{C}-\mathrm{C}$ and $\mathrm{C}-\mathrm{X}(\mathrm{X}=\mathrm{O}, \mathrm{N}$, and $\mathrm{S})$ bonds. ${ }^{11-14}$ In contrast, there has been a paucity of studies on the selective photoredox aliphatic C-C bond cleavage reaction. Most of the current protocols in photoredox bond cleavage chemistry involve the activation of prefunctionalized alkyl or aryl halides, or the loss of volatile and stable $\mathrm{CO}_{2}$ from carboxylates and carboxylate derivatives. ${ }^{15-18}$ Consequently, despite its potential for facilitating novel synthetic pathways in late-stage organic transformations or valorizing neglected feedstocks such as lignin or recycled plastics, there have been few reports that present $\mathrm{C}-\mathrm{C}$ activation of aliphatic $\mathrm{sp}^{3}$ carbons, especially by visible light at ambient temperatures and pressures. ${ }^{19-21}$

Our team has been active in creating the constituents of artificial photosynthetic constructs, including multielectron (photo)catalysts for both reduction and oxidation processes, with exclusive use of only earth-abundant 
elements. $^{22-24}$ For instance, we have employed nickel complexes in their reduced -ate forms for the electrocatalytic reduction of $\mathrm{CHCl}_{3}$ and also the evolution of $\mathrm{H}_{2}$ from seawater in separate studies. To achieve an integrated artificial photosynthetic unit without sacrificial reagents, the electrons needed for the reduction processes can be derived from commensurate (photo)catalytic oxidative half reactions (Figure 1a). In accord with this objective, we have recently presented molecular vanadium $(V)$ oxo photocatalysts that mediate remarkable oxidative $\mathrm{C}-\mathrm{C}$ bond cleavage of biomass lignin model compounds under atmospheric conditions at ambient temperatures. ${ }^{24} \mathrm{~A}$ number of distinct lignin model compounds were viable substrates, although phenolic groups inhibited the catalysis. Through density functional theory (DFT) calculations, we discovered that our vanadium(V) catalyst, bearing a redox non-innocent conjugated hydrazone-imidate ligand, can absorb visible light via a ligand-to-metal charge transfer (LMCT) to activate the $\mathrm{sp}^{3} \mathrm{C}-\mathrm{C}$ bonds of coordinated alcohol substrates under ambient conditions. The DFT studies also revealed that phenols inhibit the catalysis since the aliphatic $\mathrm{C}-\mathrm{C}$ bond cleavage in phenol substrates has high activation barriers, in excess of $30 \mathrm{kcal} \mathrm{mol}^{-1} .^{24}$

a

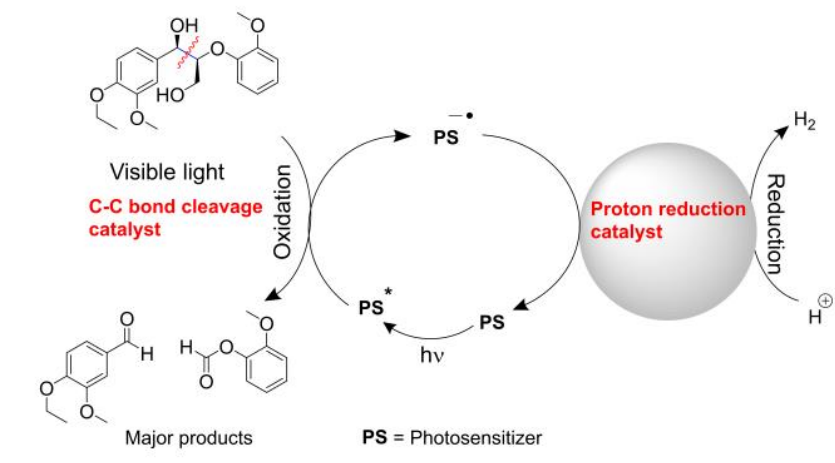

b

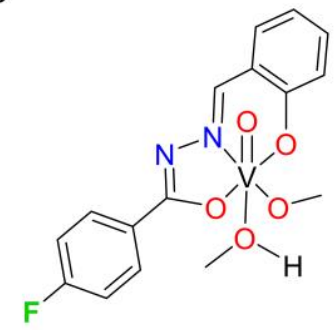

C

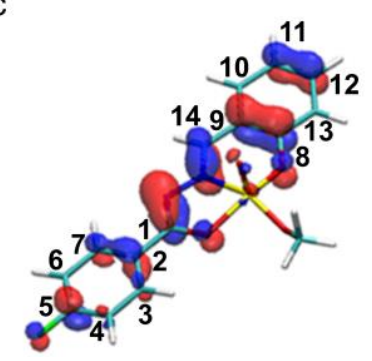

Figure 1. (a) An integrated artificial photosynthetic system comprising an oxidative photocatalytic C-C bond cleavage and a proton reduction catalytic cycle. (b) The structure of our previously published catalyst $\mathbf{2 b}$, and (c) the spatial distribution of the HOMO of $\mathbf{2 b}$ (adapted from our previous work in reference 24 ).

Herein, we draw upon the insights obtained from our prior DFT calculations and experiments to systematically design a family of new vanadium(V) photocatalysts, with electron-withdrawing substituents introduced to select positions on the aryl rings of the ligand to increase the oxidative strength. To compare the intrinsic catalytic behavior of the new catalysts through our experimental and computational investigations, we have used a new substrate that is structurally analogous to our previous lignin model, but does not hydrolyze to form phenolic secondary products. This substrate undergoes $\mathrm{C}-\mathrm{C}$ bond cleavage 2.5-17 times faster than the lignin model compound that we previously used and is currently a benchmark in this study. Through our kinetics studies, photochemical quantum yield measurements, and DFT calculations, we have developed a new photocatalyst that is up to 7 times faster than our original vanadium complex, and up to 15 times faster than the slowest catalyst in our new library of candidates. We have also gained new insights to guide the expansion of our substrate scope in future research.

\section{Results and Discussion}

\section{Design and structural characterization of new pho- tocatalysts}

The vanadium complex $\mathbf{2 b}$ (Figure $\mathbf{1 b}$ ), supported by a hydrazone-imidate ligand tautomer, can selectively activate specific $\mathrm{sp}^{3} \mathrm{C}-\mathrm{C}$ bonds of coordinated alcohol substrates as illustrated in Figure 1a, under visible light irradiation and ambient conditions. ${ }^{24}$ The prior DFT calculations suggested that the highest occupied molecular orbital (HOMO) of $\mathbf{2 b}$ (Figure 1c) is distributed mainly on the corresponding ligand $\mathbf{1 b}$. In particular, greater orbital amplitude was observed on carbon atoms 2, 3, 5, and 7 on the aryl ring containing a fluorine atom, as well as carbons 8, 9, 11, and 12 of the other aryl ring (Figure 1c). We previously showed that one of the two unpaired electrons produced after homolytic $\mathrm{C}-\mathrm{C}$ bond cleavage is transferred to the ligand HOMO that has been oxidized and become singly occupied as a result of LMCT. ${ }^{24}$ This electron transfer process during the $\mathrm{C}-\mathrm{C}$ bond cleavage should be more efficient if the HOMO energy level is lower.

We hypothesized that the incorporation of the electron withdrawing groups at the sites with the highest orbital density in the HOMO would most effectively lower the HOMO energy level. This could potentially increase the oxidative strength of the corresponding complex, which may also create faster photoredox catalysts if the charge transfer process is the rate-determining step. With this in mind, we proceeded to synthesize a series of new hydrazone-amide ligands and their corresponding vanadium complexes (Figure 2). The detailed synthetic procedures of the ligands and the corresponding complexes are described in the Supporting Information (SI). Besides $\mathbf{2 b}$, which we recently reported, the remaining complexes are new derivatives. The redox non-innocent ligands 1a-f were synthesized via condensation reactions between the corresponding hydrazides and the substituted 2hydroxybenzaldehydes, using our previously published procedure. $^{24,25}$ Due to the short synthetic route and facile 
reaction conditions with affordable, commercially available precursors, we are able to expand our library of vanadium catalysts rapidly to screen for the most active and robust variant.
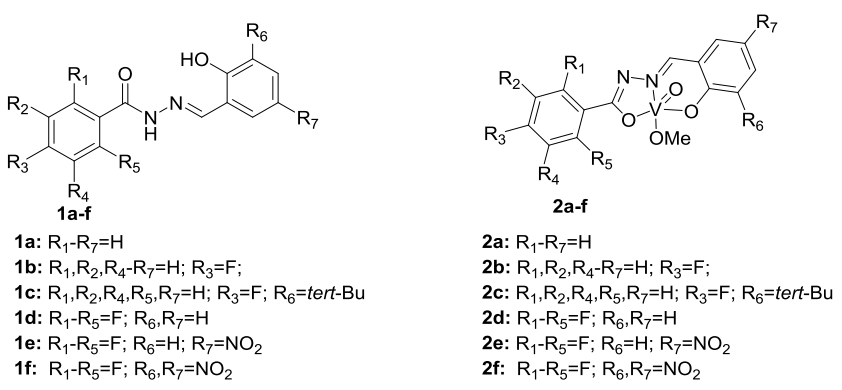

Figure 2. Hydrazone amide ligands (1a-f) and the corresponding vanadium complexes (2a-f) investigated in this study.

In the presence of 1a-f and a stoichiometric equivalent of the vanadium precursor, vanadium(V) oxytriisopropoxide, complexes $\mathbf{2 a - f}$ were prepared in high yields and fully characterized. Complex $\mathbf{2 b}$, which was presented in our previous work, has been included in the current study as a benchmark. Single crystals of $2 \mathbf{2 a}$ and $\mathbf{2 d - f}$ have been isolated by slow evaporation of methanol at room temperature, and their X-ray crystallographic structures are depicted in Figure 3.

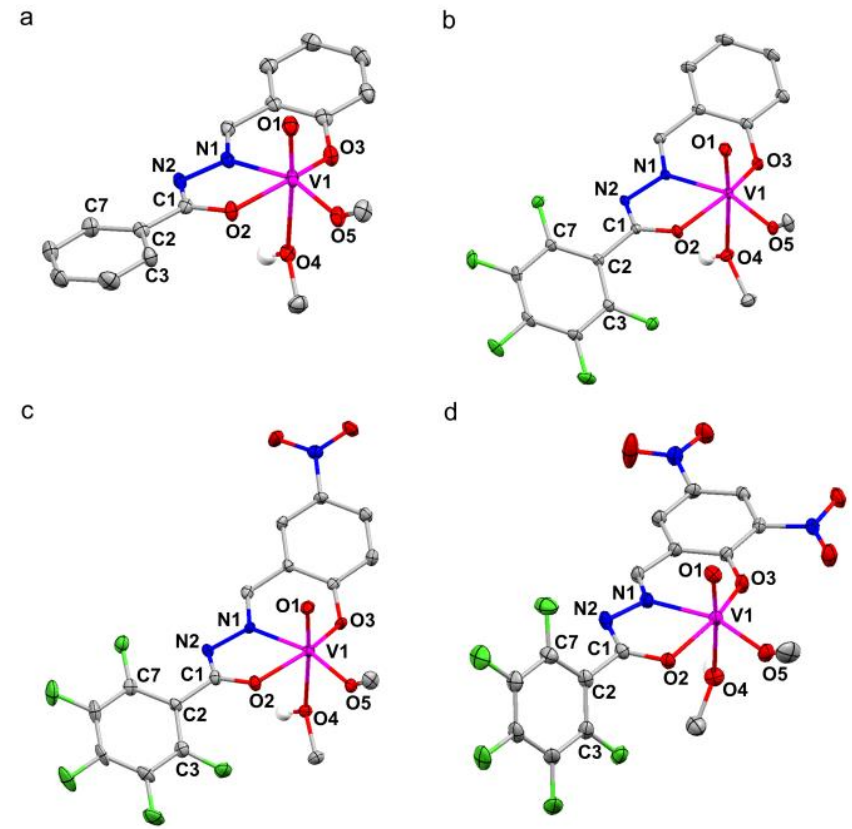

Figure 3. Oak Ridge thermal ellipsoid plots (ORTEPs) from single crystal X-ray diffraction experiments on (a) 2a, (b) 2d, (c) 2e, and (d) 2f. The fluorine, nitrogen, oxygen and vanadium atoms are shown in green, blue, red, and pink colors, respectively. All hydrogen atoms (except the one for the methanol ligand) have been omitted for clarity.

None of our attempts to crystallize 2c succeeded, although we do not anticipate any major differences be- tween $\mathbf{2 c}$ and the remaining complexes. Furthermore, $\mathbf{2 a - f}$ have been thoroughly characterized by other techniques including ${ }^{1} \mathrm{H},{ }^{13} \mathrm{C},{ }^{51} \mathrm{~V}$, and ${ }^{19} \mathrm{~F}$ (where present) NMR spectroscopy, UV-visible spectroscopy, high-resolution mass spectrometry (HRMS), and elemental analyses.

Each of the complexes displays a homologous octahedral geometry in the solid state with an equatorial methoxide and an axial methanol bound to the vanadium center. As anticipated, the vanadium-methanol V-O bond distance is elongated compared to the vanadium-methoxide bond, and the characteristic oxo $\mathrm{V}=\mathrm{O}$ bond lengths for $\mathbf{2 a}, \mathbf{2 d}$, 2e, and 2 f are found to be $1.59,1.588,1.581$, and $1.584 \AA$ respectively. There appears to be no correlation between the electron-withdrawing ability of the ligands and the bond lengths. Interestingly, the aryl ring of the imidate arm of the ligand is distorted from the equatorial plane to different extents, likely due to steric influence from the ortho fluorine groups. The torsion angles $(\psi)$ of the $\mathrm{O}_{2}$ $\mathrm{C}_{1}-\mathrm{C}_{2}-\mathrm{C}_{3}$ moiety are $1.19^{\circ}, 35.97^{\circ}, 34.56^{\circ}$, and $53.92^{\circ}$ for $\mathbf{2 a}$, $\mathbf{2 d}, \mathbf{2 e}$, and $\mathbf{2 f}$, respectively. Other salient parameters of the complexes are summarized in the SI (Tables S1-S2o).

\section{Substrates for photocatalytic C-C bond cleavage}

With 2a-f in hand, we proceeded to investigate their photoredox catalytic activity for $\mathrm{C}-\mathrm{C}$ bond cleavage reactions. To evaluate and compare the relative activities of the catalysts, two compounds 7 and 8 were used as representative substrates (Scheme 1). Substrate 7 had been used as one of the substrates that demonstrated selective $\mathrm{C}-\mathrm{C}$ bond cleavage in our previous study with $\mathbf{2 b}$, but it was later found to form secondary products that inhibited the catalyst. ${ }^{24}$

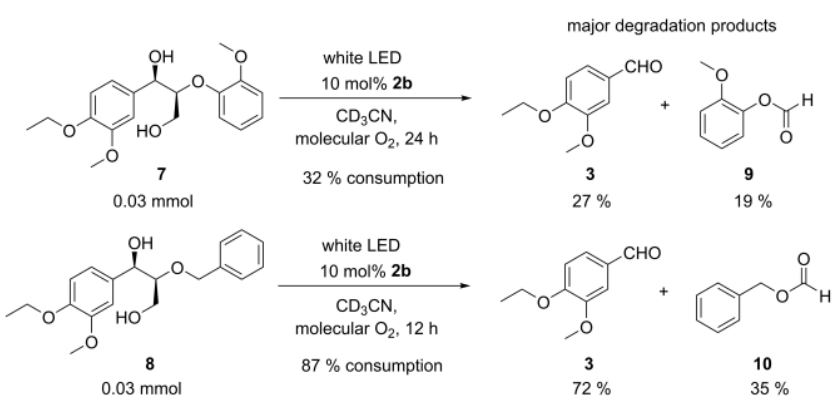

Scheme 1. Product distribution after selective $\mathrm{C}-\mathrm{C}$ bond cleavage of $\mathbf{7}$ and $\mathbf{8}$ under visible light irradiation and ambient temperatures and pressures.

Over the course of the photodriven $\mathrm{C}-\mathrm{C}$ bond cleavage using $\mathbf{2 b}$ as a catalyst, $\mathbf{7}$ yields an aryl formate $\mathbf{9}$ as one of the products. Compound $\mathbf{9}$ was found to slowly hydrolyze during the reaction to produce guaiacol, a phenol that may irreversibly bind to $\mathbf{2 b}$ and thus appeared to be a catalyst poison for $\mathbf{2 b}$. The lower $\mathrm{pK}_{\mathrm{a}}$ of the phenol in guaiacol than the aliphatic alcohols of 7 , coupled with the higher aliphatic $\mathrm{C}-\mathrm{C}$ bond cleavage activation barrier 
when the substrate is bound through a phenol, suggested that guaiacol would slowly and irreversibly inactivate $\mathbf{2 b}$.

In an attempt to avoid this catalyst inhibition sidereaction and facilitate our kinetics studies, which may guide us in identifying the fastest candidate among our new vanadium photocatalysts, we designed and prepared $\mathbf{8}$ as an alternative substrate. Unlike $7, \mathbf{8}$ would potentially undergo selective photocatalytic $\mathrm{C}-\mathrm{C}$ bond cleavage under the same reaction conditions to give a benzyl formate (1o, Scheme 1) instead. Secondary hydrolysis of 10 during photocatalysis will generate a benzyl alcohol rather than a phenol, which should not competitively inhibit our vanadium catalysts. Moreover, we expect that 8 may undergo selective $\mathrm{C}-\mathrm{C}$ cleavage more readily since the resultant radical should be stabilized by more effective hyperconjugation with a benzyloxy than with a phenoxy group, which is supported by our new DFT calculations (vide infra). Hence, $\mathbf{8}$ is likely to provide us with insights into the intrinsic activity of our catalysts in shorter time with fewer side-reaction complications than 7 under the photoredox catalytic conditions.

The detailed synthetic procedure of $\mathbf{8}$ can be found in the SI (Scheme 4 ). Briefly, 8 was synthesized in two steps beginning with 3-methoxy-4-ethoxybenzaldehyde (3) and methyl 2-(benzyloxy)acetate (5'). The first step involves $\mathrm{C}-\mathrm{C}$ bond formation via a nucleophilic attack by the car- banion from 5' on the aldehyde in 3 to yield 6'. Reduction of the methyl ester in 6' by $\mathrm{NaBH}_{4}$ gave the primary alcohol 8.

\section{Selective photocatalytic C-C bond cleavage of 7 and 8}

After successful syntheses of the new library of vanadium catalysts and the two substrates, we sought to optimize the photocatalytic reaction conditions for the originally reported $\mathbf{2 b}$, and also establish the products after photolysis of the new substrate 8. Instead of using a $300 \mathrm{~W}$ solar simulator as we did in our previous study, we conducted each photocatalytic degradation experiment with a more operationally convenient and affordable $48 \mathrm{~W}$ light emitting diode (LED) as the white light source. Continuous ambient condition water circulation around the reaction vessel maintained the reaction temperatures below $30^{\circ} \mathrm{C}$. The reactions were each conducted in a sealed NMR tube with $30.0 \mu \mathrm{mol}$ of substrate, $3.0 \mu \mathrm{mol}$ of $\mathbf{2 b}(10 \mathrm{~mol} \%$ ), and $30.0 \mu \mathrm{mol}$ of 1,1,2,2-tetrachloroethylene as an (unreactive) internal standard in $0.6 \mathrm{~mL}$ of $\mathrm{CD}_{3} \mathrm{CN}$ as the solvent. An oxygen balloon was used to introduce a controlled 1 atm aerobic environment and minimize solvent evaporation. After $24 \mathrm{~h}$ of visible light irradiation in the described setup, ${ }^{1} \mathrm{H}$ NMR spectroscopy was used to determine the conversion and product yields (Figure 4).

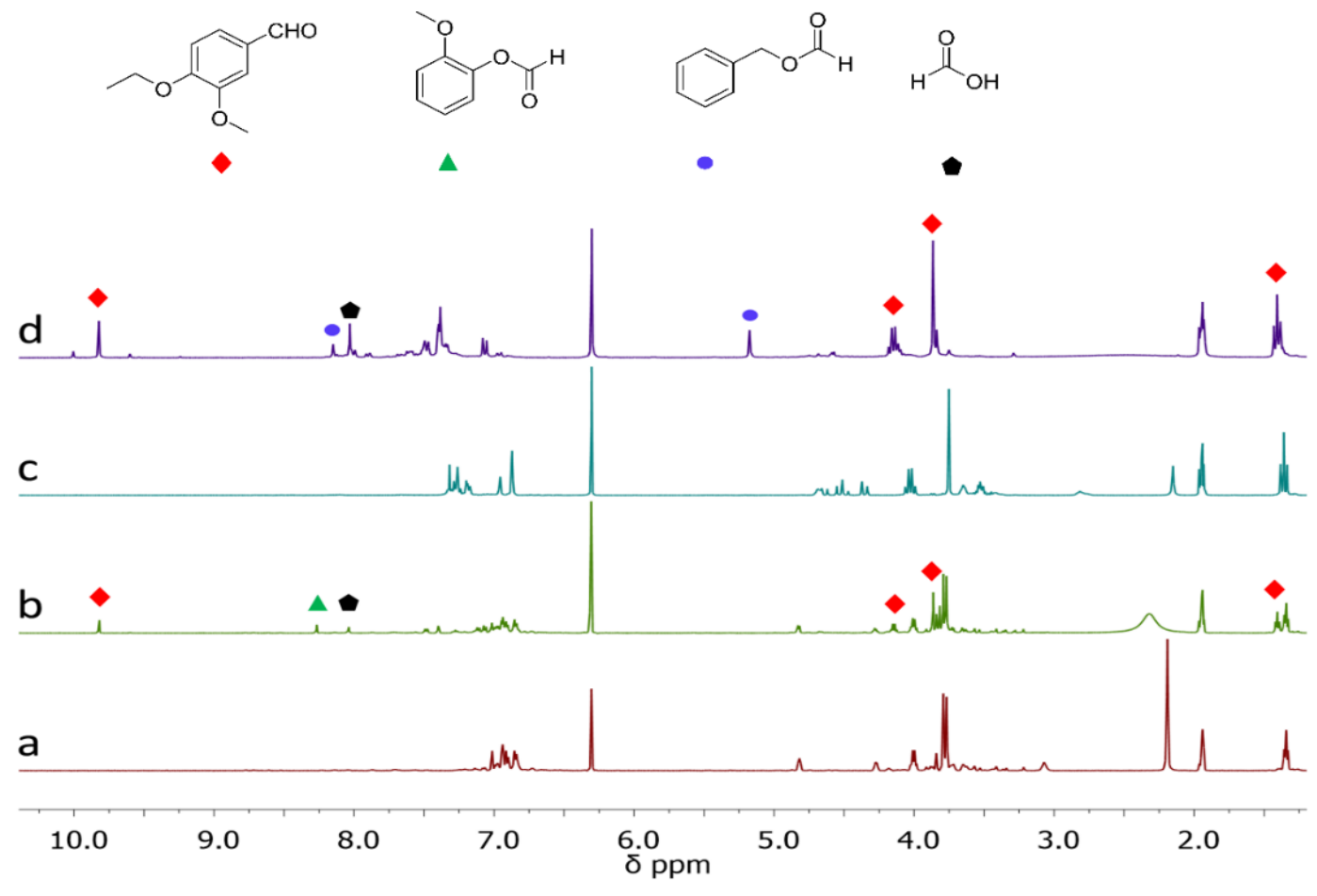

Figure 4. The ${ }^{1} \mathrm{H}$ NMR spectra of a reaction mixture containing 7 (30.0 $\left.\mu \mathrm{mol}\right)$, $\mathbf{2 b}(3.0 \mu \mathrm{mol}, 10 \mathrm{~mol} \%)$, and an internal standard 1,1,2,2-tetrachloroethylene $(30.0 \mu \mathrm{mol})$ in $\mathrm{CD}_{3} \mathrm{CN}(\mathrm{a})$ before, and (b) after $24 \mathrm{~h}$ of irradiation with a $48 \mathrm{~W}$ white LED. The ${ }^{1} \mathrm{H}$ NMR spectra of a reaction mixture containing 8 (30.0 $\left.\mu \mathrm{mol}\right)$, $\mathbf{2 b}$ (3.0 $\left.\mu \mathrm{mol}, 10 \mathrm{~mol} \%\right)$, and an internal standard 1,1,2,2-tetrachloroethylene (30.0 $\mu \mathrm{mol}$ ) in $\mathrm{CD}_{3} \mathrm{CN}$ (c) before, and (d) after $12 \mathrm{~h}$ of irradiation with a $48 \mathrm{~W}$ white LED. Continuous room temperature water circulation through a transparent glass vessel around the NMR rube was used to maintain the temperatures below $30^{\circ} \mathrm{C}$ during illumination. The peak at $6.30 \mathrm{ppm}$ corresponds to the internal standard. 
Table 1. Photocatalytic reaction of $\mathbf{7}$ and $\mathbf{8}$ with catalysts $\mathbf{2 a - 2 f}$, distribution of the products, and the product yields. ${ }^{\ddagger}$

\begin{tabular}{|c|c|c|c|c|c|c|c|c|c|c|c|}
\hline \multirow[t]{2}{*}{ Catalyst } & \multicolumn{2}{|c|}{$\begin{array}{l}\text { Consumption of } \\
\text { substrates }(\%)\end{array}$} & \multicolumn{3}{|c|}{$\begin{array}{l}\text { Distributions of the products } \\
\text { and yields }(\%)\end{array}$} & \multirow{2}{*}{$\begin{array}{c}\text { Consumption of } \\
\text { substrates (\%) } \\
8\end{array}$} & \multicolumn{5}{|c|}{$\begin{array}{c}\text { Distributions of the products } \\
\text { and yields (\%) }\end{array}$} \\
\hline & 7 & 3 & 9 & & & & 3 & 10 & & & \\
\hline $2 a$ & 31 & 26 & 17 & 8 & 10 & 85 & 71 & 36 & 18 & o6 & 28 \\
\hline $2 b$ & 32 & 27 & 19 & 10 & 11 & 87 & 72 & 35 & 18 & 14 & 36 \\
\hline $2 c$ & 22 & 15 & 10 & 4 & 5 & 84 & 70 & 33 & 19 & o8 & 32 \\
\hline $2 d$ & 61 & $5^{2}$ & 31 & 10 & 14 & 89 & 82 & 40 & 15 & 11 & 38 \\
\hline $2 e$ & 76 & 68 & 51 & 14 & 16 & 93 & 88 & 54 & 21 & 12 & 33 \\
\hline $2 f$ & 55 & 46 & 29 & 10 & 12 & 88 & 81 & 39 & 20 & 10 & 34 \\
\hline
\end{tabular}

‡ The substrate consumption $\%$ and the product yields are calculated based on the ${ }^{1} \mathrm{H}$ NMR spectra in the presence of an internal standard 1,1,2,2-tetrachloroethylene. The total irradiation time for $\mathbf{7}$ and $\mathbf{8}$ are $24 \mathrm{~h}$ and $12 \mathrm{~h}$, respectively.

Other spectroscopic techniques $\left({ }^{13} \mathrm{C}\right.$ NMR spectroscopy and HRMS) were employed to confirm the product identities after silica gel chromatographic purification. With $\mathbf{2 b}$, only around $32 \%$ of 7 was consumed (\% relative to 1,1,2,2-tetrachloroethylene) via selective $\mathrm{C}-\mathrm{C}$ bond cleavage (Scheme 1, Table 1) to form $3(27 \%)$ and 2methoxyphenyl formate (9, 19\%). Remarkably, under the same photocatalytic conditions, rapid consumption of $\mathbf{8}$ was observed within only $12 \mathrm{~h}$ of irradiation. Around $87 \%$ of 8 was converted to yield $3(72 \%)$ and $10(35 \%)$ as the major reaction products via the analogous selective C-C bond cleavage (Scheme 1, Table 1). Gratifyingly, 8 reacts faster than 7 under the same photocatalytic conditions with $\mathbf{2 b}$, concurring with our prior hypothesis. The control experiments with $\mathbf{8}$ were also carried out in the absence of catalysts under visible light irradiation, as well as in the presence of selected catalysts $(\mathbf{2 b}, \mathbf{2 c}$, and $\mathbf{2 e})$ with heating at $80{ }^{\circ} \mathrm{C}$ in the dark. The reactions were monitored by ${ }^{1} \mathrm{H}$ NMR spectroscopy in the presence of $1,1,2,2-$ tetrachloroethylene as the internal standard under otherwise similar conditions as above. Only $7 \%$ of 8 reacted and a trace amount (5\%) of 3 was observed after $24 \mathrm{~h}$ of visible light irradiation. Under thermal conditions, the ketone (30\%) derived from benzylic alcoholic oxidation of 8 was observed only in the presence of $10 \mathrm{~mol} \% \mathbf{2 e}$ after $\mathbf{2 4} \mathrm{h}$, whereas $\mathbf{8}$ did not react in the presence of $\mathbf{2 b}$ and $\mathbf{2 c}$ at $80{ }^{\circ} \mathrm{C}$. With the conditions for the $\mathrm{C}-\mathrm{C}$ bond cleavage in the substrates established, we subsequently sought the most active vanadium catalyst among those in our new library (2a-f) by monitoring the trends in their activity with both 7 and 8 .

\section{Kinetics studies on the photocatalytic C-C bond cleavage by $2 \mathrm{a}-\mathrm{f}$}

As part of the kinetics studies, a series of photodriven oxidative $C-C$ bond cleavage reactions of 7 and 8 were conducted in the presence of $\mathbf{2 a - f}$ as catalysts. Each experiment was conducted under the same reaction conditions as those reported above, and the measurement for every catalyst was repeated at least twice. The substrate conversion in 2 and $4 \mathrm{~h}$ intervals has been monitored by ${ }^{1} \mathrm{H}$ NMR spectroscopy, and the results are summarized in Figure 5. Among 2a-f, their photocatalytic rates differ several-fold. Figures $5 \mathrm{a}$ and $5 \mathrm{~b}$ patently demonstrate that 8 underwent $\mathrm{C}-\mathrm{C}$ bond cleavage 3 to 17 times faster than 7 , with an obvious trend in rate between the catalysts $2 \mathrm{a}-\mathbf{2 f}$. After $24 \mathrm{~h}$ of visible light irradiation, only $22 \%$ of 7 reacted in the presence of $\mathbf{2 c}$, whereas the conversion reached $76 \%$ in the presence of $2 \mathbf{e}$ (Figure $5 \mathrm{a}$ ). On the other hand, the consumption of $\mathbf{8}$ had reached their maximum values exceeding $80 \%$ for all catalysts $2 a-f$ within 12 h, with most reaching steady concentrations after only $8 \mathrm{~h}$ of visible light irradiation (Figure $5 \mathrm{~b}$ ).

The nonlinear decay in substrate concentration, $C_{t} / C_{o}$, in Figures $5 \mathrm{a}$ and $5 \mathrm{~b}\left(C_{t}\right.$ represents the substrate concentration at time $t$ and $C_{o}$ is the initial substrate concentration) suggest a first or higher order dependence of the rate law on the substrate. Accordingly, in the plots of $\ln \left(C_{t} / C_{o}\right)$ against time for both substrates, linear fits to the data gave reasonable agreement (Figures $5 \mathrm{c}$ and $5 \mathrm{~d}$ for $\mathbf{7}$ and $\mathbf{8}$, respectively), indicating that the rate law has a first order dependence on substrate concentration since the oxidant $\mathrm{O}_{2}$ is present in large excess. 
a

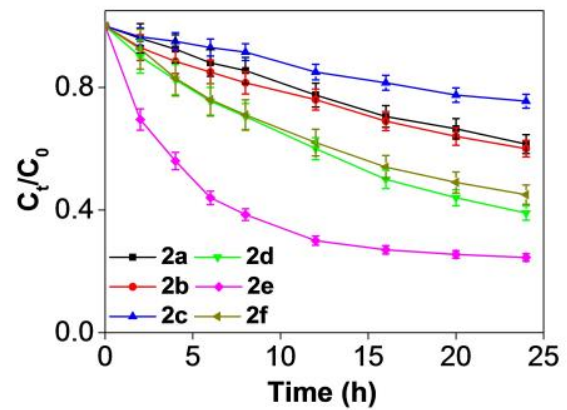

C

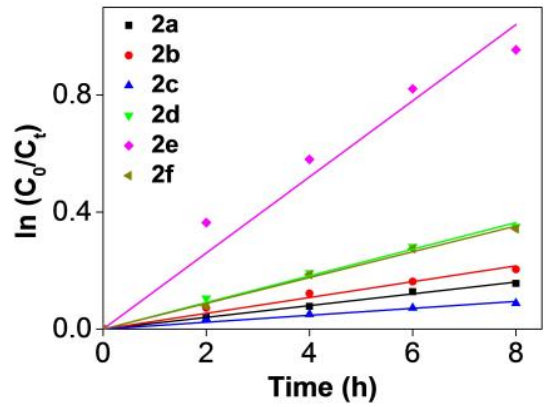

b

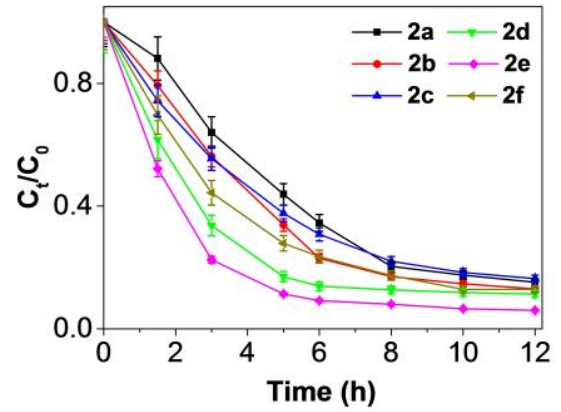

d

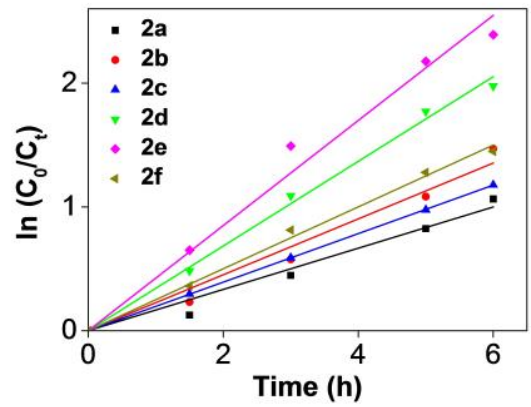

Figure 5. Kinetics plots for the decay of (a) 7 and (b) 8 during irradiation with photocatalysts 2 a-f, where $C_{t}$ represents the substrate concentration at time $t$ and $C_{o}$ is the initial concentration. The colored lines connecting the data points for each catalyst are meant as guides. Plots of $\ln \left(C_{\mathrm{o}} / C_{t}\right)$ versus time for $(\mathrm{c}) \mathbf{7}$, and (d) 8 in the presence of different photocatalysts $2 a-f$, where the slope of the best linear fit provides the pseudo first-order rate constant $k$. In the figures, the data for each catalyst are represented as follows: $\mathbf{2 a}$ (black squares), $\mathbf{2 b}$ (red circles), 2c (blue triangles), $2 \mathbf{d}$ (green inverted triangles), $\mathbf{2 e}$ (pink diamonds), and $\mathbf{2 f}$ (olive tilted triangles).

a

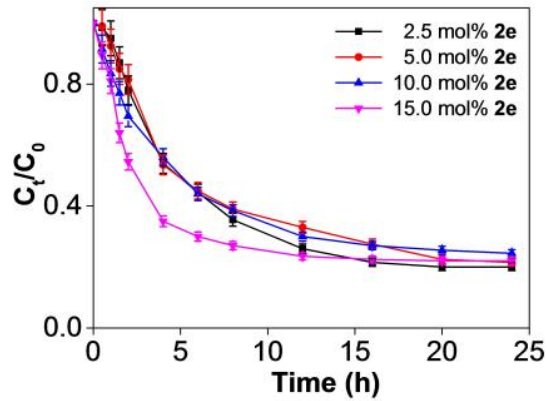

C

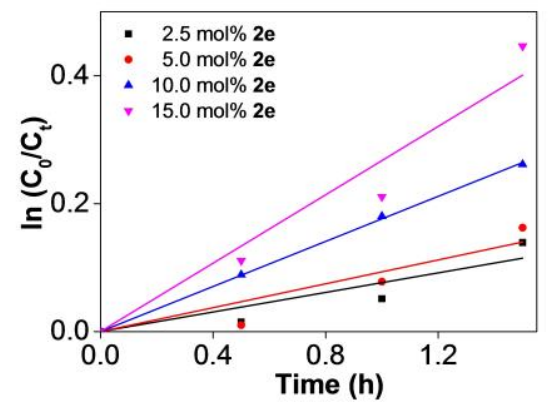

b

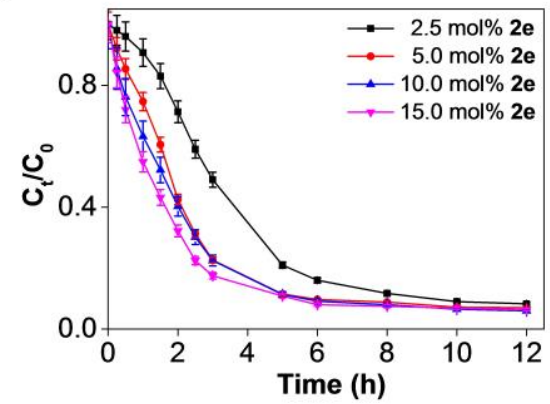

d

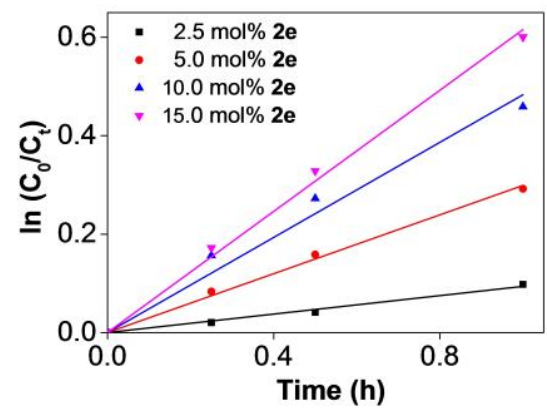

Figure 6. Kinetics plots for the decay of (a) 7 and (b) 8 during irradiation with different amount of photocatalyst 2e, where $C_{t}$ represents the substrate concentration at time $t$ and $C_{o}$ is the initial concentration. The colored lines connecting the data points for each catalyst are meant as guides. Plots of $\ln \left(C_{\mathrm{o}} / C_{t}\right)$ versus time for (c) 7 , and (d) 8 in the presence of different amounts of $\mathbf{2 e}$, where the slope of the best linear fit provides the pseudo first-order rate constant $k$. In the figures, the data for each catalyst are represented as follows: $2.50 \mathrm{~mol} \%$ of $2 \mathbf{e}$ (black squares), 5.0 mol\% of $2 \mathbf{e}$ (red circles), $10.0 \mathrm{~mol} \%$ of $2 \mathbf{e}$ (blue triangles), $15.0 \mathrm{~mol} \%$ of $\mathbf{2 e}$ (pink inverted triangles). 
Moreover, to determine the dependence of the rate on the catalyst, kinetics experiments have been conducted by varying the amount of the photocatalyst. The most active catalyst 2e was chosen and the amount of the catalyst was varied from 2.5 to $15 \mathrm{~mol} \%$ relative to the substrates, while the initial concentration of the substrates was fixed at $30.0 \mu \mathrm{mol}$. The kinetics results are summarized in Figure 6. It is evident that the decay of 7 (Figure 6a) or 8 (Figure 6b) is enhanced with increasing concentrations of 2e. To obtain the initial rates at low conversions $(1.5 \mathrm{~h}$ for $\mathbf{7}$ and $\mathbf{~ h}$ for 8) for different concentrations of $2 \mathrm{e}$, reasonable linear fits to the plots of $\ln C_{o} / C_{t}$ versus time could be made (Figure $6 c$ for 7 and Figure $6 \mathrm{~d}$ for 8 ). The deviation from linearity at lower 2 e concentrations with substrate 7 could be due to the overwhelming effect from the secondary product, guaiacol, which could coordinate irreversibly to inactivate the catalyst during the photoreaction. The pseudo first order rate constants of the reactions between $\mathbf{7}$ or $\mathbf{8}$ with different concentrations of $\mathbf{2 e}$ were then calculated from the slope of the linear fits.

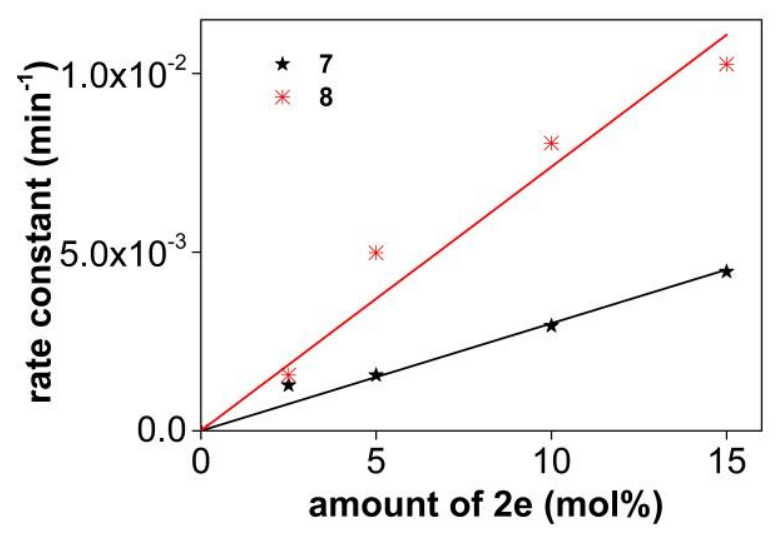

Figure 7. Almost linear increase in pseudo first order rate constant for the reactions of $\mathbf{7}$ or $\mathbf{8}$ with increasing concentrations of $\mathbf{2 e .}$

The pseudo first order rate constants increased linearly with the concentrations of ze added (Figure 7), concurring with a rate law that has a first order dependence on the catalyst concentration. A similar, apparent larger variance from linearity for $\mathbf{7}$ than for $\mathbf{8}$ is likely due to the effect of phenolic guaiacol binding, and subsequent inactivation of $2 \mathbf{e}$. From these plots, the second order initial rate constants, $k_{2 x, y}(\mathbf{2} \mathbf{x}=$ catalyst from $\mathbf{2 a}-\mathbf{f}, \mathbf{y}=$ substrate 7 or 8), were derived from the slopes of the linear fits. From the results above, the rate equation for this photocatalytic $\mathrm{C}-\mathrm{C}$ bond cleavage reaction can be expressed as follows:

$$
\text { Rate }=k^{\prime}[\mathbf{y}]=k_{2 x, y}[\mathbf{2 x}][\mathbf{y}] \quad \text { Equation } \mathbf{1}
$$

Pseudo-first order rate constant, $k^{\prime}=k_{2 x, y}[\mathbf{2 x}]$ Equation 2
The calculated kinetics parameters for the reactions of $\mathbf{7}$ and $\mathbf{8}$ in the presence of each catalyst are summarized in Table 2.

As illustrated in Figure $5 \mathrm{C}$ and Table 2, the fastest catalyst for the degradation of $\mathbf{7}$ is $\mathbf{2 e}$, which performs with an initial second order rate constant about 15 times higher than that for the slowest catalyst $\mathbf{2 c}$. The trend in decreasing order of reactivity towards 7 is $\mathbf{2 e}>\mathbf{2 d} \sim \mathbf{2 f}>\mathbf{2 b}>\mathbf{2 a}>$ 2c. For the $\mathrm{C}-\mathrm{C}$ cleavage of $\mathbf{8}$, the fastest photocatalyst is still 2e, although its initial second order rate constant is only around 2.7-fold higher than that for the slowest catalyst, which is $\mathbf{2 a}$ instead of $\mathbf{2 c}$. The more active substrate $\mathbf{8}$ resulted in poorer differentiation in activity among $\mathbf{2 a - f}$, although a similar trend in initial rate constants can be observed as $\mathbf{2 e}>\mathbf{2 d}>\mathbf{2 f}>\mathbf{2 b} \sim \mathbf{2 a}>\mathbf{2 c}$. Besides being a faster catalyst, 2e also appears to be more robust with slightly higher turnover numbers (TON), since up to $93 \%$ of 8 reacted, whereas the reaction leveled off with around $80 \%$ of $\mathbf{8}$ consumed in the presence of $\mathbf{2 a}$ and $\mathbf{2 c}$, even for prolonged photolysis.

Based on these kinetics studies, it appears that 2d-f, with pentafluoro substituents on the imidate portion of the ligand, show greater activity towards $\mathbf{7}$ and $\mathbf{8}$ than $\mathbf{2 a - c}$, which have only one or no fluorine substituent on the ligand. However, the effect of the nitro group on the aryl hydrazone part of the ligand is more subtle. The fastest catalyst is 2e, which has only one electron-withdrawing nitro group para to the phenoxide in the ligand.

On the other hand, adding a second nitro group ortho to the phenoxide in $\mathbf{2 f}$ appeared to have a detrimental effect on the photocatalytic rate, since the activity became similar to (for 7 ) or even slower (for 8 ) than that of $\mathbf{2 d}$, which has no substituents on the aryl hydrazone motif. Complexes 2a-c, with one or no electron-withdrawing substituents on the imidate part of the ligand, clearly exhibit slower reactivity regardless of the substrate. Furthermore, the introduction of an electron-donating and sterically bulky tert-butyl group on the aryl hydrazone (2c) led to even slower catalytic rates. In aggregate, our kinetics measurements agree with our initial hypothesis that incorporating electron-deficient groups on the ligand can increase the photocatalytic rate of the vanadium complexes. Critically, substitution at locations with orbital density in the HOMO can be beneficial (vide infra), or else steric or redox effects could retard the catalytic activity, as observed for $\mathbf{2 c}$ and $\mathbf{2 f}$, which have ortho substituents of opposite donor abilities. Although $2 \mathrm{f}$ was expected to be the fastest photocatalyst due to its highest oxidizing strength, we propose that the turnover could be limited by the regeneration of the catalyst. 
Table 2. Redox potentials, kinetics parameters, and quantum yields of $\mathbf{2 a - 2 f}$.

\begin{tabular}{|c|c|c|c|c|c|c|c|}
\hline \multirow[t]{2}{*}{ Complex } & \multirow{2}{*}{$\begin{array}{c}\text { Redox } \\
\text { poten- } \\
\text { tials } \\
\left(\mathrm{E}_{1 / 2}\right) \text { in } \\
\mathrm{V} \text { vs } \\
\mathrm{Fc}^{+} / \mathrm{Fc}^{2}\end{array}$} & \multicolumn{2}{|c|}{$\begin{array}{l}\text { Pseudo-first order rate con- } \\
\text { stant of consumption of sub- } \\
\text { strates }(k)\end{array}$} & \multicolumn{2}{|c|}{$\begin{array}{c}\text { Second order rate constant } \\
\text { of reaction }\left(k_{2 x, y}\right)\end{array}$} & \multicolumn{2}{|c|}{$\begin{array}{c}\text { Quantum yield of con- } \\
\text { sumption of substrates }(\phi)\end{array}$} \\
\hline & & $\begin{array}{l}k^{\prime} \text { for } 7 \\
\left(\min ^{-1}\right)\end{array}$ & $\begin{array}{l}k^{\prime} \text { for } 8 \\
\left(\min ^{-1}\right)\end{array}$ & $\begin{array}{c}k_{2 x} \text { for } 7 \\
\left(\mathrm{M}^{-1} \min ^{-1}\right)\end{array}$ & $\begin{array}{l}k_{2 x} \text { for } 8 \\
\left(\mathrm{M}^{-1} \min ^{-1}\right)\end{array}$ & $\phi$ for $7(\%)$ & $\phi$ for $8(\%)$ \\
\hline $\mathbf{2 a}$ & -0.007 & $3.35 \times 10^{-4}$ & $2.77 \times 10^{-3}$ & 0.067 & 0.554 & 0.28 & 1.76 \\
\hline $\mathbf{2 b}$ & 0.008 & $4.51 \times 10^{-4}$ & $3.76 \times 10^{-3}$ & 0.090 & $0.75^{2}$ & 0.42 & 2.13 \\
\hline $2 \mathrm{C}$ & -0.110 & $1.97 \times 10^{-4}$ & $3.26 \times 10^{-3}$ & 0.039 & 0.652 & 0.18 & 2.17 \\
\hline $2 d$ & 0.120 & $7.59 \times 10^{-4}$ & $5.70 \times 10^{-3}$ & $0.15^{2}$ & 1.140 & 0.64 & 3.25 \\
\hline $\mathbf{2 e}$ & 0.320 & $2.16 \times 10^{-3}$ & $7.07 \times 10^{-3}$ & 0.601 & 1.477 & 1.60 & $3 \cdot 79$ \\
\hline $2 f$ & 0.420 & $7.34 \times 10^{-4}$ & $4.16 \times 10^{-3}$ & 0.147 & 0.832 & 0.65 & 2.83 \\
\hline
\end{tabular}

The catalyst undergoes reduction to $\mathrm{V}^{\mathrm{IV}}$ during catalysis, and has to be re-oxidized by aliphatic peroxide radicals during the reaction. As shown in Table 3, the LUMO of $\mathbf{2 f}$ is the lowest in energy, indicating that the $\mathrm{V}^{\mathrm{IV}}$ state is easily generated in this case. The regeneration of the $\mathrm{V}^{\mathrm{V}}$ photocatalyst via one electron oxidation at the vanadium center is expected to be thermodynamically least favorable. This hypothesis was also supported by our observation that the initial dark red color of $\mathbf{2} \mathbf{f}$ and the substrate turned green during the course of the irradiation. We had seen the formation of intractable, green colored $\mathrm{V}^{\mathrm{IV}}$ products in our previous report. This change was not perceptible for 2a-e, suggesting that aerobic oxidation back to $\mathrm{V}^{\mathrm{V}}$ for $\mathbf{2} \mathrm{f}$ could be slower or hindered.

Overall, the new kinetics measurements concur with the DFT calculations in our previous paper, where the ratedetermining step was found to be the photoinduced $\mathrm{C}-\mathrm{C}$ bond cleavage reaction. Consequently, there is a first order dependence of the reaction rate separately on the catalyst and the substrate concentration, and a zeroth order dependence on the $\mathrm{O}_{2}$ concentration, since reoxidation of the catalyst by $\mathrm{O}_{2}$ takes place after the ratedetermining step. We have also created a new photocatalyst $2 \mathbf{e}$ that is up to 7 times faster than our original $\mathbf{2 b}$, and up to 15 times faster than the slowest $2 \mathrm{C}$ in our conveniently expandable, new library of $\mathrm{C}-\mathrm{C}$ bond cleavage catalysts.

\section{Electrochemical and DFT studies}

In order to examine if the trends in catalytic rate among 2a-f were partly due to higher redox potentials and hence stronger oxidation strengths, cyclic voltammetry (CV) measurements and DFT calculations were conducted on the vanadium complexes. The voltammograms showing the first oxidative wave of $2 \mathbf{a}-\mathbf{f}$ are displayed in Figure 8. All the complexes exhibited one reversible $\mathrm{V}^{\mathrm{V}} / \mathrm{V}^{\mathrm{IV}}$ redox wave in the electrochemical window that we investigated, with the half-wave potentials $\left(E_{1 / 2}\right)$ summarized in Table 2. As anticipated, the CV data revealed that $\mathbf{2 f}$, which pos- sessed the largest number of electron-withdrawing functional groups, had the highest redox potential (olive line, Figure 8), whereas $\mathbf{2 c}$ with the electron-rich tert-butyl substituent has the lowest potential (blue line, Figure 8). The trend in redox potentials was found to be $\mathbf{2 f}>\mathbf{2 e}>\mathbf{2 d}$ $>\mathbf{2 b} \sim \mathbf{2} \mathbf{a}>\mathbf{2 c}$, which was consistent with the reduction in the number of electron-withdrawing substituents in the ligand.

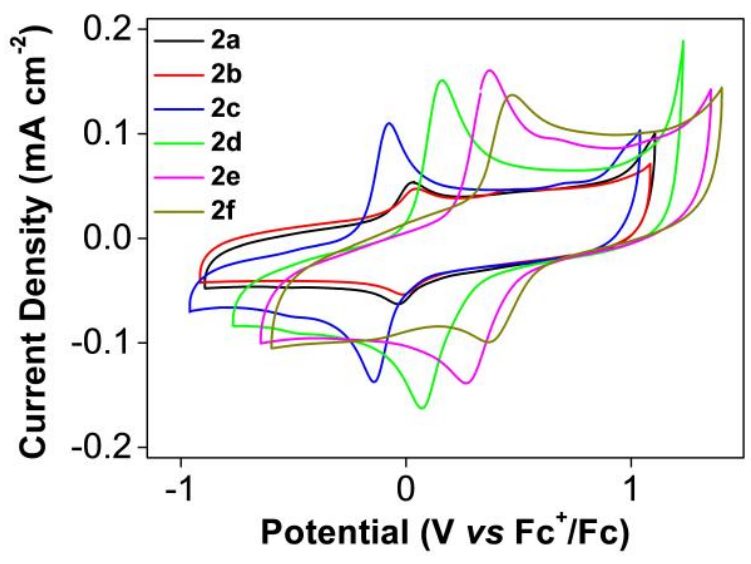

Figure 8. Cyclic voltammograms (CVs) of $1.0 \mathrm{mM}$ of $\mathbf{2 a}$ (black), $\mathbf{2 b}$ (red), 2c (blue), $\mathbf{2 d}$ (green), 2e (magenta), and

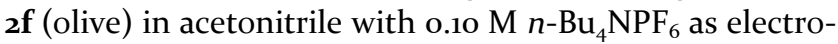
lyte. The potentials are reported relative to the $\mathrm{Fc}^{+} / \mathrm{Fc}$ redox couple. Decamethylferrocene was used as an internal standard to avoid overlapping redox waves with our complexes.

The para-fluoro group in $\mathbf{2 b}$ may be too remote and not sufficiently electron-withdrawing like mesomeric nitro groups to dramatically increase the redox potentials compared to 2a. This trend in redox potentials from $\mathrm{CV}$ measurements also correlated with the electronic energies of the HOMO in $\mathbf{2 a - f}$ (Table 3) obtained by DFT calculations. The DFT calculations using Gaussian $09^{26-27}$ suggest that 2f has the lowest HOMO energy level, 
whereas 2c has the highest HOMO energy among our library of vanadium photocatalysts. The increasing order of HOMO energies of $\mathbf{2 a - f}$ match the trend from $\mathrm{CV}$ measurements: $\mathbf{2 f}>\mathbf{2 e}>\mathbf{2 d}>\mathbf{2 b} \sim \mathbf{2 a}>\mathbf{2 c}$.

Table 3. HOMO and LUMO energies (in $\mathrm{eV}$ ) of $\mathbf{2 a - 2 f}$.

\begin{tabular}{ccc}
\hline Complexes & HOMO & LUMO \\
\hline $\mathbf{2 a}$ & -5.961 & -3.291 \\
$\mathbf{2 b}$ & -5.964 & -3.300 \\
$\mathbf{2 c}$ & -5.954 & -3.269 \\
$\mathbf{2 d}$ & -5.970 & -3.387 \\
$\mathbf{2 e}$ & -6.000 & -3.577 \\
$\mathbf{2 f}$ & -6.098 & -3.723 \\
\hline
\end{tabular}

Both the electrochemical experiments and the calculated electronic properties indicate that the stronger oxidants 2d-f are thermodynamically more favorable for the $\mathrm{C}-\mathrm{C}$ bond cleavage in $\mathbf{7}$ and $\mathbf{8}$ than $\mathbf{2 a - c}$, which have fewer electron-deficient substituents. The DFT calculations also revealed that in the reactions with $\mathbf{2 a - d}$, the LMCT involved electronic transitions from HOMO-1 to LUMO, followed by a $\mathrm{C}-\mathrm{C}$ bond cleavage in the $\mathrm{T}_{1}$ state. In the cases of $\mathbf{2 e}$ and $\mathbf{2 f}$, the LMCT is associated with electronic transition from $\mathrm{HOMO}-2$ to LUMO. Furthermore, the DFT calculations verified that $\mathrm{C}-\mathrm{C}$ bond cleavage in $\mathbf{8}$ should be faster than 7. Using the previous calculations of 2b with $\mathbf{7}$ as a benchmark, the activation energies for the photocatalytic C-C bond cleavage of $\mathbf{8}$ with $\mathbf{2 a - 2 f}$ were lower by $2.9-9.3 \mathrm{kcal} \mathrm{mol}^{-1}$ in the $\mathrm{S}_{1}$ state and by 4.3 to 8.9 $\mathrm{kcal} \mathrm{mol}^{-1}$ in the $\mathrm{T}_{1}$ state (Table 4 ).

Table 4. Activation energy from the ground state for the C-C bond cleavage photocatalyzed by $\mathbf{2 a - 2 f}$ via LMCT.

\begin{tabular}{cccc}
\hline Complex & Substrate & $\begin{array}{c}\Delta \mathrm{E}^{\ddagger}\left(\mathrm{S}_{1}\right) \\
\left(\mathrm{kcal} \mathrm{mol}^{-1}\right)\end{array}$ & $\begin{array}{c}\Delta \mathrm{E}^{\ddagger}\left(\mathrm{T}_{1}\right) \\
\left(\mathrm{kcal} \mathrm{mol}^{-1}\right)\end{array}$ \\
\hline 2b & 7 & 25.7 & 28.2 \\
2a & $\mathbf{8}$ & 20.3 & 23.2 \\
2b & 8 & 20.1 & 23.1 \\
2c & $\mathbf{8}$ & 22.8 & 23.9 \\
2d & $\mathbf{8}$ & 20.5 & 22.7 \\
2e & $\mathbf{8}$ & 16.4 & 19.6 \\
2f & $\mathbf{8}$ & 17.3 & 19.3 \\
\hline
\end{tabular}

A plausible reason for the lower activation energy in the cleavage of $\mathbf{8}$ could be the greater stability of the radical species formed as a result of homolytic C-C bond cleavage. We anticipated that the $\mathrm{C}-\mathrm{C}$ bond adjacent to the benzyl alcohol in $\mathbf{8}$ may be weaker than the analogous bond in $\mathbf{7}$, since the resultant radical for the former ( $\mathbf{a}$ in Scheme 2) should be stabilized by hyperconjugation more effectively.

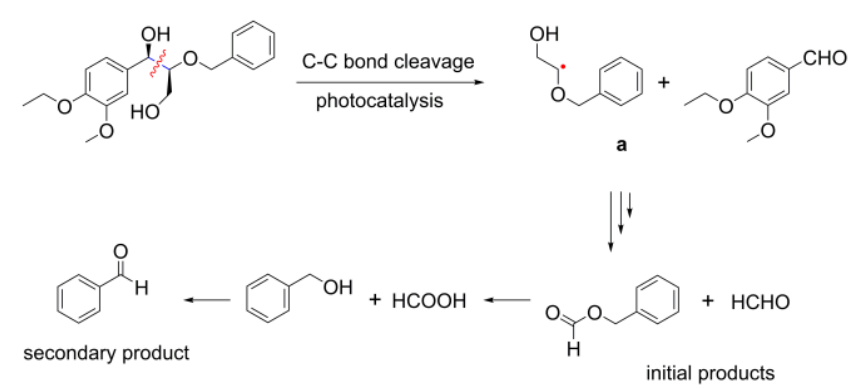

Scheme 2. C-C bond cleavage of 8 under visible light irradiation with white LED.

The two $\mathrm{sp}^{3}$ hybridized pairs from the benzyloxy group in radical a can potentially be more effective in distributing the spin density of the radical than a phenoxy group, which has one of its lone pairs taken up by mesomeric interactions with the aryl ring. The radicals are then expected to react with molecular $\mathrm{O}_{2}$, which presumably produces formaldehyde initially, but eventually leads to the corresponding formate and other oxidized products. A characteristic peak at 9.60 ppm was observed in the ${ }^{1} \mathrm{H}$ NMR spectrum, which might be attributed to formaldehyde, although it was likely to be further oxidized or polymerized under our reaction conditions. Hydrolysis or oxidation of the formates may then occur to yield guaiacol (for 7) or benzyl alcohol and benzaldehyde (for 8) as secondary products. ${ }^{24}$ Likewise, these calculations concur with our observed product distribution by ${ }^{1} \mathrm{H}$ NMR spectroscopy.

\section{Photophysical measurements on 2a-f}

To better understand and explain the photocatalytic reactivity of 2a-f, their photophysical properties have also been investigated. Figure 9a depicts the UV-vis absorption spectra of $\mathbf{2 a}-\mathbf{f}$, all of which have absorption bands in the visible region up to about $500 \mathrm{~nm}$, arising from LMCT transitions. ${ }^{24}$ Complexes $\mathbf{2 a}$ and $\mathbf{2 b}$ have almost identical LMCT absorption bands with the maxima residing at around $396 \mathrm{~nm}$, whereas $\mathbf{2 c}$ and $\mathbf{2 d}$ absorb less light above $396 \mathrm{~nm}$. Notably, 2e and 2f have the most blue-shifted LMCT bands with maxima around $355 \mathrm{~nm}$ (Figure 9, inset). Since all the photocatalysts have similar visible light absorption and emission profiles, we conducted quantum yield measurements to explore if the fraction of light absorbed by $2 \mathbf{a}-\mathbf{f}$ affected the reaction rates. We used the standard ferrioxalate as the chemical actinometer to estimate the fraction of light absorbed by $2 \mathbf{a}-\mathbf{f}$ at $436 \mathrm{~nm}$, and hence the quantum yield of the photocatalytic degradation of $\mathbf{7}$ and $\mathbf{8}$. The details of the quantum yield measurements are shown in the $\mathrm{SI}^{28-29}$ We chose $436 \mathrm{~nm}$ because the quantum yield of ferrioxalate at $436 \mathrm{~nm}$ is reported to be 1.11, and the results are summarized in Table 
2. Based on the quantum yield measurements on the photochemical consumption of $\mathbf{7}$, 2e clearly has the highest quantum efficiency $(1.60 \%)$, while $2 \mathrm{c}$ showed the lowest quantum efficiency (o.18\%). Complexes $\mathbf{2 d}$ and $\mathbf{2 f}$ showed comparable results (0.64\% and $0.65 \%$ respectively).

a

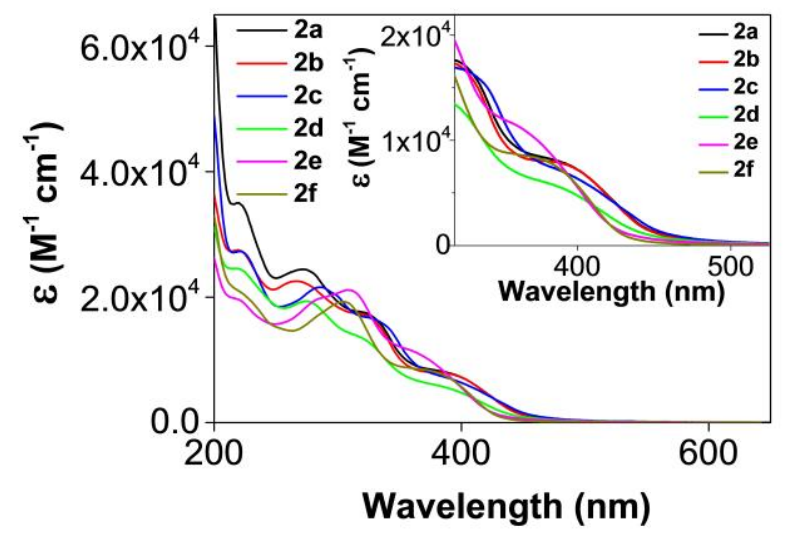

b

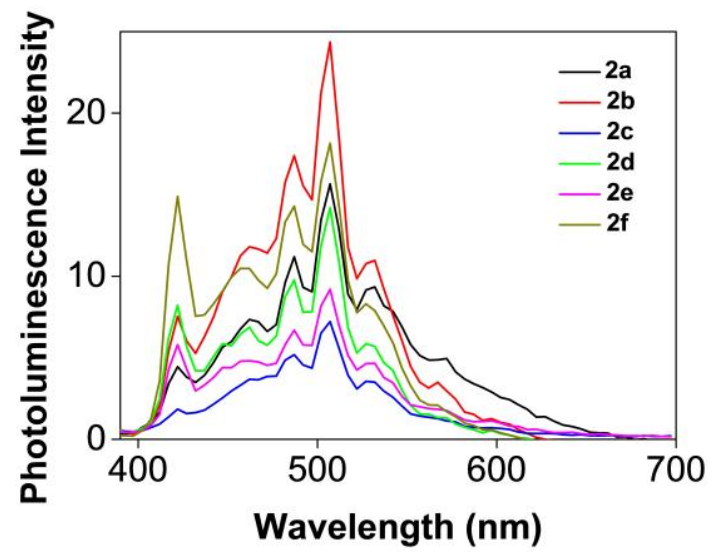

Figure 9. (a) UV-vis absorption spectra of o.10 $\mathrm{mM}$ solutions of $2 \mathbf{a}$ (black), $\mathbf{2 b}$ (red), 2c (blue), 2d (green), $2 \mathbf{e}$ (magenta), and $\mathbf{2 f}$ (olive) in acetonitrile. The inset shows the LMCT band of the complexes. (b) Photoemission spectra of $0.50 \mathrm{mM}$ solutions of $\mathbf{2 a}-\mathbf{f}$ with excitation at 370 $\mathrm{nm}$ in acetonitrile. The spectra have the same color scheme as part (a).

Similarly, for the photolysis of $\mathbf{8}$, $\mathbf{2}$ demonstrated the highest quantum efficiency (3.79\%) but 2 a had the lowest quantum efficiency $(1.76 \%)$, although all the complexes exhibited higher efficiencies for the $\mathrm{C}-\mathrm{C}$ bond cleavage in 8. Thus, the trend in photochemical quantum efficiencies for $2 \mathbf{a}-\mathbf{f}$ correlated well with their redox potentials and rates in the photocatalytic degradation of $\mathbf{7}$ and $\mathbf{8}$ under ambient aerobic conditions.

\section{Conclusion}

In summary, we have synthesized a class of new molecular $V^{V}$ oxo complexes (2a-f) as visible light active photocatalysts with redox non-innocent hydrazone-amide lig- ands (1a-f). A catalytic amount of these complexes can selectively activate and subsequently cleave the aliphatic $\mathrm{C}-\mathrm{C}$ bond of representative alcohol substrates $\mathbf{7}$ and $\mathbf{8}$ to yield value-added fine chemicals like aryl aldehydes, aryl formates, and benzyl formates. These are important building blocks in organic synthesis as they contain reactive formyl groups that can be further functionalized.

Our experimental studies revealed that $\mathbf{2 e}$, which possesses more electron withdrawing groups, showed the highest yielding and fastest activity towards the $\mathrm{C}-\mathrm{C}$ bond cleavage reaction, up to 15 times faster than the slowest catalyst 2c, which possesses electron-donating tert-butyl substituents on the ligand. The kinetics and DFT studies indicated that the substrate 8 is $2.5^{-17}$ times more reactive than 7 towards $\mathrm{C}-\mathrm{C}$ bond cleavage under our photocatalytic degradation conditions. Although 2f, possessed the highest calculated and also electrochemically determined redox potential, it was found to be less reactive than $\mathbf{2 e}$. We propose that the regeneration of the $\mathrm{V}^{\mathrm{V}}$-active catalyst from the $\mathrm{V}^{\mathrm{IV}}$ resting state for $\mathbf{2 f}$ is slower than that for $\mathbf{2 e}$, which reduces the overall reaction rate for $\mathbf{2 f}$. In our experimental and DFT investigations, the introduction of electron-withdrawing groups at select locations on the ligand has been critical in increasing the reaction yield and catalytic rate. We believe a substrate scope expansion should be feasible, since we have identified the ratedetermining step of the process and verified that higher stability of the radical intermediate favors faster reactivity. This study paves the way for future research on LMCT driven $\mathrm{C}-\mathrm{C}$ bond activation by our vanadium photoredox catalysts with improved light absorption capabilities.

\section{ASSOCIATED CONTENT}

Supporting Information. Detailed synthetic procedures of the ligands, $\mathrm{V}^{\mathrm{V}}$ oxo complexes, and the model substrates, and their thorough characterizations. Essential crystallographic data, photocatalytic experimental procedures, quantum yield measurements, and data from DFT calculations. This material is available free of charge via the Internet at http://pubs.acs.org.

\section{AUTHOR INFORMATION}

\section{Corresponding Author}

* E-mail: hansen@ntu.edu.sg

*E-mail: hhirao@cityu.edu.hk

\section{ACKNOWLEDGMENT}

H. S. S. is supported by an NTU start-up grant (M4081012), the Nanyang Assistant Professorship (M4081154), and an MOE Tier 1 grant (M4011611). The authors acknowledge the support from the Solar Fuels Laboratory at NTU and the Singapore-Berkeley Research Initiative for the Sustainable Energy (SinBeRISE) CREATE Programme. This research program is funded by the National Research Foundation (NRF), the Prime Minister's Office, Singapore under its Campus for Research Excellence and Technological Enterprise (CREATE). The authors also gratefully acknowledge the Agency for Science, Technology and Research (A*STAR), AME IRG grant 
A1783cooo2, for funding this research. H. H. thanks City University of Hong Kong (7200534 and 9610369) for financial support.

\section{REFERENCES}

1. Cuthbertson, J.; MacMillan, D. W. C. Nature 2015, 519, 74-77.

2. Zuo, Z.; Ahneman, D. T.; Chu, L.; Terrett, J. A.; Doyle, A. G.; MacMillan, D. W. C. Science 2014, 345, 437-440.

3. Pirnot, M. T.; Rankic, D. A.; Martin, D. B. C.; MacMillan, D. W. C. Science 2013, 339, 1593-1596.

4. Devery, J. J., III; Douglas, J.; Nguyen, J.; Cole, K.; Flowers Ii, R.; Stephenson, C. R. J. Chem. Sci. 2015, 6, 537-541.

5. Furst, L.; Narayanam, J. M.; Stephenson, C. R. Angew. Chem., Int. Ed. 2011, 50, 9655-9659.

6. Wei, G.; Zhang, C.; Bureš, F.; Ye, X.; Tan, C.-H.; Jiang, Z. ACS Catal. 2016, 6, 3708-3712.

7. Levin, M.; Kim, S.; Toste, F. D. ACS Cent. Sci. 2016, 2, 293-301.

8. Amador, A.; Sherbrook, E.; Yoon, T. J. Am. Chem. Soc. 2016, 138, 4722-4725.

9. Xiao, Q.; Sarina, S.; Bo, A.; Jia, J.; Liu, H.; Arnold, D.; Huang, Y.; Wu, H.; Zhu, H. ACS Catal. 2014, 4, 17251734 .

10. Ding, W.; Lu, L. Q.; Liu, J.; Liu, D.; Song, H. T.; Xiao, W. J. J. Org. Chem. 2016, 81, 7237-7243.

11. Corcoran, E. B.; Pirnot, M. T.; Lin, S.; Dreher, S. D.; DiRocco, D. A.; Davies, I. W.; Buchwald, S. L.; MacMillan, D. W. C. Science 2o16, 353, 279-283.

12. Terrett, J.; Cuthbertson, J.; Shurtleff, V.; MacMillan, D. W. C. Nature 2015, 524, 330-334.

13. Shaw, M. H.; Shurtleff, V. W.; Terrett, J. A.; Cuthbertson, J. D.; MacMillan, D. W. C. Science 2016, 352, 1304-1308.

14. Luo, J.; Zhang, J. ACS Catal. 2016, 6, 873-877.

15. Johnston, C.; Smith, R.; Allmendinger, S.; MacMillan, D. W. C. Nature 2016, 536, 322-325.

16. Zuo, Z.; Cong, H.; Li, W.; Choi, J.; Fu, G. C.; MacMillan, D. W. C. J. Am. Chem. Soc. 2016, 138, 1832-1835.

17. Nawrat, C.; Jamison, C.; Slutskyy, Y.; MacMillan, D. W. C.; Overman, L. J. Am. Chem. Soc. 2015, 137, 1127011273 .

18. Douglas, J.; Sevrin, M.; Stephenson, C. R. J. Org. Process Res. Dev. 2016, 20, 1134-1147.

19. Lee, S.; Fung, H.; Feng, S.; Chan, K. Organometallics 2016, 35, 2480-2487.
20. Sun, H.; Yang, C.; Gao, F.; Li, Z.; Xia, W. Org. Lett. 2013, 15, 624-627.

21. Cai, S.; Zhao, X.; Wang, X.; Liu, Q.; Li, Z.; Wang, D. Z. Angew. Chem., Int. Ed. 2012, 51, 8050-8053.

22. Das, S. P.; Ganguly, R.; Li, Y.; Soo, H. S. Dalton Trans. 2016, 45, 13556-13564.

23. Shao, H.; Muduli, S.; Tran, P.; Soo, H. S. Chem. Commun. 2016, 52, 2948-2951.

24. Gazi, S.; Hung Ng, W.; Ganguly, R.; Putra Moeljadi, A.; Hirao, H.; Soo, H. S. Chem. Sci. 2015, 6, 7130-7142.

25. Wang, L.; Qin, W.; Tang, X.; Dou, W.; Liu, W. J. Phys. Chem. A 2011, 115, 1609-1616.

26. Gaussian 09, Revision D.o1, Frisch, M. J.; Trucks, G. W.; Schlegel, H. B.; Scuseria, G. E.; Robb, M. A.; Cheeseman, J. R.; Scalmani, G.; Barone, V.; Mennucci, B.; Petersson, G. A.; Nakatsuji, H.; Caricato, M.; Li, X.; Hratchian, H. P.; Izmaylov, A. F.; Bloino, J. Z., G.; Sonnenberg, J. L.; Hada, M.; Ehara, M.; Toyota, K.; Fukuda, R.; Hasegawa, J.; Ishida, M.; Nakajima, T.; Honda, Y.; Kitao, O.; Nakai, H.; Vreven, T.; Montgomery, J. A., Jr.; Peralta, J. E.; Ogliaro, F.; Bearpark, M.; Heyd, J. J.; Brothers, E.; Kudin, K. N.; Staroverov, V. N.; Kobayashi, R.; Normand, J.; Raghavachari, K.; Rendell, A.; Burant, J. C.; Iyengar, S. S.; Tomasi, J.; Cossi, M.; Rega, N.; Millam, M. J.; Klene, M.; Knox, J. E.; Cross, J. B.; Bakken, V.; Adamo, C.; Jaramillo, J.; Gomperts, R.; Stratmann, R. E.; Yazyev, O.; Austin, A. J.; Cammi, R.; Pomelli, C.; Ochterski, J. W.; Martin, R. L.; Morokuma, K.; Zakrzewski, V. G.; Voth, G. A.; Salvador, P.; Dannenberg, J. J.; Dapprich, S.; Daniels, A. D.; Farkas, Ö.; Foresman, J. B.; Ortiz, J. V.; Cioslowski, J.; Fox, D. J. Gaussian, Inc., Wallingford CT, 2009.

27. See the SI for technical details of DFT calculations.

28. Hatchard, C. G.; Parker, C. A. Proc. R. Soc., Ser. A 1956, 235, 518-536.

29. Kuhn, H. J.; Braslavsky, S. E.; Schmidt, R. Pure Appl. Chem. 2004, 76, 2105-2146. 


\section{Table of Contents}

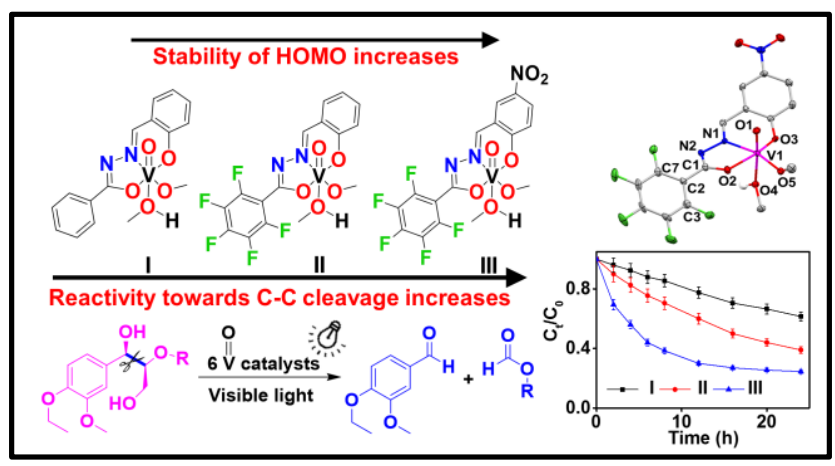

